\title{
Research on Layout Optimization of Villages in Poverty-Stricken Counties -A Case Study of Wangmo County, Guizhou, China
}

\author{
Shuai Zhang ${ }^{1}$, Lin Zhu $^{2 *}$, Weili Wang ${ }^{3}$ \\ ${ }^{1}$ School of Geographical Science, Southwest University, Chongqing 400715, China \\ ${ }^{2}$ College of State Governance, Southwest University, Chongqing 400715, China \\ ${ }^{3}$ Primary school, Taiyuan University of Technology, Shanxi 030024, China
}

Corresponding Author Email: zl2013@swu.edu.cn

https://doi.org/10.18280/ijsdp.160411

Received: 11 May 2021

Accepted: 26 July 2021

\section{Keywords:}

rural spatial layout, smart shrinkage, village-town system, Wangmo County

\begin{abstract}
Against the background of rural revitalization in China, this study takes Wangmo County as the study area, and uses mathematical models such as entropy method and rank-size rule to quantitatively evaluate the rural development potential of Wangmo County and rural development scale and hierarchical structure in Wangmo County. Based on this, the study puts forward suggestions for village layout optimization. According to the results, (i) evaluation elements of rural subject, industrial development, resource endowment, and habitat environment in Wangmo County are presented in the spatial pattern of being scattered as a whole and be agglomerated locally. (ii) The rank-size distribution of village is that there are more villages in the medium-ranking position, while there are fewer high-and-low-ranking villages with spindle structure of "being small on both ends, and large in the middle", showing that the agglomeration of village elements has a weak degree of spatial polarization. (iii) By comprehensively evaluating results and field investigation situation, a township hierarchy of central village-general village-merged village is constructed to divide the development types of three rural areas, including agglomeration type for improvement, equilibrium, and stable type, as well as relocation and merger type. The results of the study in the case area can provide a reference for the local scientific response to the decreasing trend of rural population and change the predicament of low efficiency of public resource allocation caused by small-scale and scattered distribution of the rural areas.
\end{abstract}

\section{INTRODUCTION}

With the advancement of urbanization and industrialization, the continuous decrease in the rural permanent population is a common problem in both developed and developing countries [1]. China has witnessed shrinkage of varying degrees in the developed eastern regions or the underdeveloped western regions under the interaction of multiple factors such as the slowdown in economic growth and regional competition differentiation [2, 3]. The "Key Tasks for New Urbanization Construction and Urban-Rural Integration Development in 2020" proposes to facilitate quick settlement of non-registered population such as agricultural transfer population in cities, constantly increase the urbanization rate and promote the transfer of agricultural population to urban areas. In that case, rural permanent population and rural human settlement space demands will witness a sustained reduction along with the main development trend of rural shrinkage $[4,5]$. What's more, some villages with insufficient capabilities of responding to external environmental changes and disturbances will be vanished gradually [6]. In the context of rural revitalization, the smart shrinkage theory is essential for implementing "smart growth" of the overall development using "smart shrinkage" in local areas, so that the demands of rural development can be satisfied on the premise of scientifically dealing with the declining trend of rural population.
"Smart shrinkage" is a management model proposed by Germany for addressing problems of population loss and economic recession during the socialist period of Eastern Europe [7]. This model has emerged when existing urban problems and emerging problems of the gentrification movement cannot be fundamentally resolved in the growthoriented development model. And smart shrinkage is also defined as less planning- less people, less buildings, and less land utilization [8], which underlines the formation of conceptual transitions from the pursuit of economic growth to the enhancement of living quality in the face of urban recession $[9,10]$. Currently, most studies of smart shrinkage focus more on urban development, which have effectively guided the revival of declining cities [11]. However, it should be noted that shrinkages of varying degrees are also confronted by small towns and rural areas besides cities [12, 13]. Although the smart shrinkage theory still cannot be universally applied to the development of cities and towns in China, it can provide a novel theoretical perspective for the intensive and sustainable development in rural areas since the reason for its emergence is similar to that of the current population shrinkage and land expansion in rural areas of China. For instance, Scholar Zhao Min constructed a development framework for smart shrinkage of rural settlement space, and concluded that "cities are developing smartly, while rural areas are shrinking smartly" after applying smart shrinkage theory 
to the field of rural human settlement space [5]. Besides, some scholars also carried out research on layout optimization for rural human settlement space and proposed corresponding development strategies against the particularity and representativeness of rural human settlement space in different areas based on smart shrinkage theory. For example, You Lie introduced the SGME (small-scale settlement, group arrangement, micro pastoral scenery and ecological construction) model to provide a reference for improving the efficiency in resource supply, coordinate the relationship among residential agglomeration, spatial layout adjustment, industrial development, and infrastructure layout with a case study in Chengdu [14]. Besides, Long Hualou offered an innovative approach for implementing smart shrinkage in rural areas through reconstructing the rural spaces from population concentration, spatial optimization, and industrial agglomeration [15]. Peters et al. interpreted influencing factors of smart shrinkage from dimensions of population, economy, social capital, and civic participation to disclose the shrinkage path of small towns on the premise of constructing an entrepreneurial social infrastructure analysis framework [16].

Most existing studies proposed a smart shrinkage scheme for rural human settlement space for a specific village, whereas smart shrinkage for villages in counties is rarely studied. As the top-level design for coordinating the whole area, counties play an instructive role in rural development. Hence, studying the optimization of village layout at the county level with the help of smart shrinkage theory is of great practical significance for integrating and optimizing the village-town system, spatial layout of the village, and configuration of public service facilities. Wangmo County, a poverty-stricken area located in Guizhou, China, was selected as the research area. On this basis, the development potential of the village and its rank-size distribution feature were evaluated scientifically to identify its development pattern. Subsequently, smart shrinkage and layout schemes were proposed for villages, so that the theoretical system of smart shrinkage can be enriched to provide a novel theoretical perspective for rural areas with similarities in territory to seek transformation paths and their planning responses.

Wangmo County, Guizhou, China is located in a contiguous poor area of Yunnan, Guangxi and Guizhou with rocky desertification, which is one of the impoverished counties in China. And the topography of the county is high in the north and low in the south. Covering an area of $3,018.44 \mathrm{~km}^{2}$, the county has 16 towns and 163 administrative villages, as shown in Figure 1. Evidently, permanent population of Wangmo is decreased from 292,700 in 2014 to 276,400 in 2020, showing a shrinking trend, while the size of land use is increased from $102.82 \mathrm{~km}^{2}$ in 2014 to $132.2 \mathrm{~km}^{2}$ in 2020 , presenting a trend of "people shrinking and landing expanding". Hence, smart shrinkage is an urgent task in Wangmo county.

Research data are composed of socio-economic data and spatial data. To be specific, the socio-economic data were obtained from the Wangmo County Rural Economic Report and the Wangmo County Statistical Yearbook at the same period, while the spatial data were from the Natural Resources Bureau. Limited by the availability of data, the research used only 2019 data. Among the 163 villages in the county, Wangmu Village, Hedong Community and Hexi Community are excluded from the research area for they are part of the urban area.

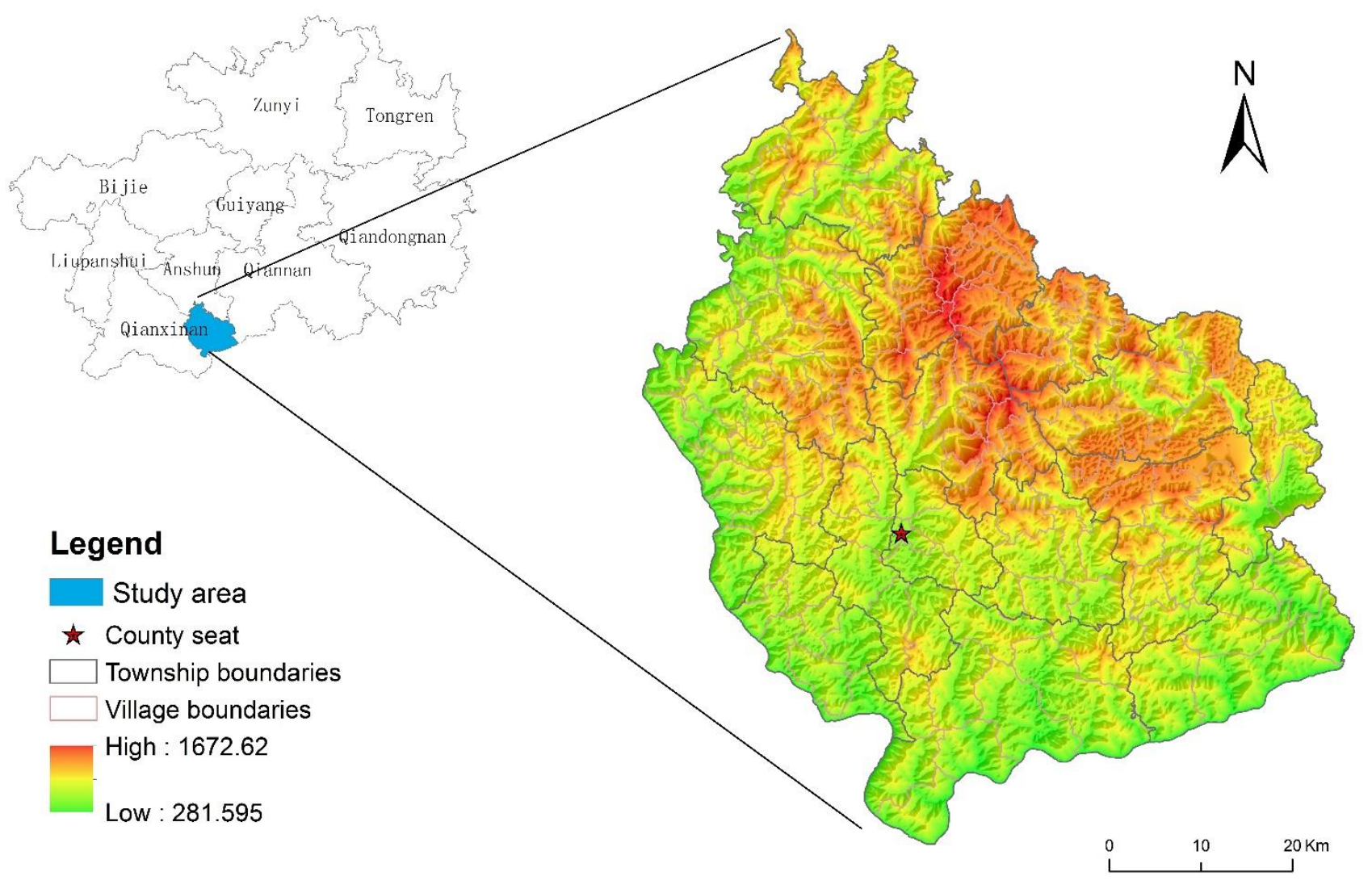

Figure 1. Location of the case study 


\section{THEORETICAL BASIS}

The rural region system is an open system with certain structures and functions, which is constituted by interactions of various elements such as natural endowments, locations, economic foundation, human resources, and cultural customs within a certain rural area [17]. From the perspective of structure, the rural region system consists of the central system and the peripheral system of rural development [15]. The process of rural development and evolution is, in essence, a dynamically-evolution course that elements inside the rural areas are continuously optimized and reconstructed to promote constant evolutions in structure and functions under the influences of external environments, such as globalization, urbanization, industrialization, and regional policy adjustments. Among them, villages with apparent advantages in resource endowments and geographic location develop faster than other villages, and thus become regional centers for element agglomeration and diffusion [18], which are connected to surrounding villages via transportation routes and rivers. However, some villages with adverse natural environments, poor resource endowments, and insufficient capabilities to cope with disturbance of external environment will vanish gradually [19]. Urban and rural infrastructure and public services have been improved in the process of rural development along with the continuous development of social economy. Also, the flow between urban and rural elements has become more sufficient. Moreover, the rural village system has gradually evolved from a disordered state to an ordered state, while the spatial structure of the rural area has been changed from a low-level equilibrium stage of single-point distribution to a high-level equilibrium stage of point-domain integration thanks to the advancement in linear transportation and rivers. Overall, the regional development and evolution of rural areas have undergone an evolution process from scattered-point distribution, point-to-point connection, to point-tomultipoint connection, and point-to-domain integration [20], which have experienced the inefficient and balanced development stage, the stage of dominant villages being polarized, the stage of elements enhancing each other, and the urban-rural interaction and integration stage at the spatiotemporal level (as shown in Figure 2).

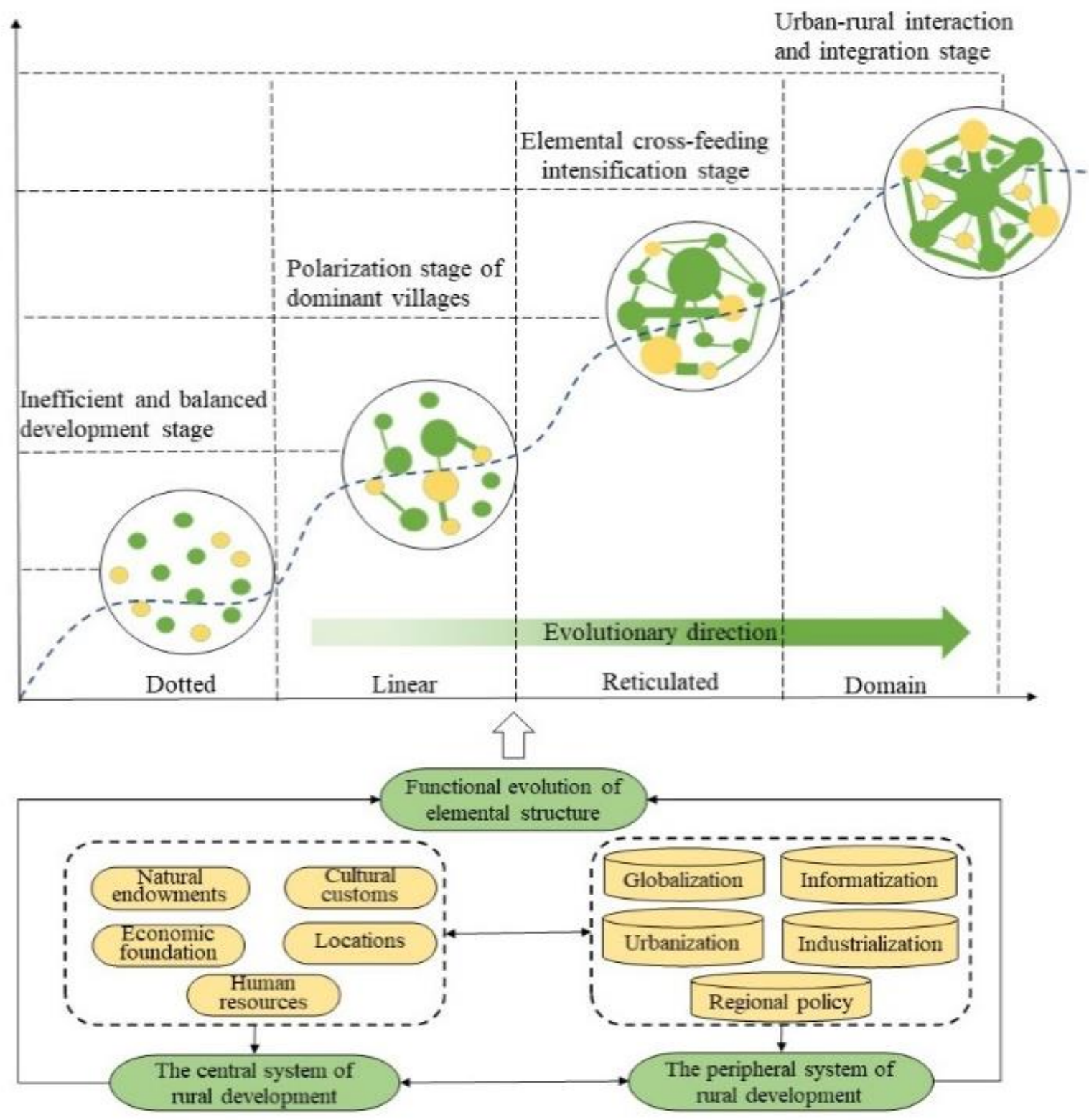

Figure 2. Illustration of the development of the village 
With development as its core value orientation, smart shrinkage theory refers to vacating or replacing inefficient lands through planned deployment of spatial resources under limited social resources [5]. From the rural perspective, guided by the aim of optimizing the structure and function of the rural system, smart shrinkage of village is to implement structural optimization and functional optimization of spatial structure in the rural area through reconstructing system elements such as population, industry, and space based on the stage characteristics of social and economic development in rural areas. From the regional perspective, smart shrinkage of village is to push forward the "growth" of social and economic benefits in the entire area through "shrinking" the population and construction land in some parts. On the one hand, concerning villages with favorable socio-economic development, the continuous growth of the overall regional benefits in the optimized area and the dynamic development of rural areas were implemented under the control of the overall development trend of the area, the agglomeration of internal space, and functional optimization. On the other hand, regarding villages with unsatisfactory socio-economic development, the strategy of land shrinkage and resource withdrawal was implemented to merge villages. In this way, low efficiency of public resource allocation, lack of vitality in villages, poor production and living conditions of farmers and the like dilemmas caused by villages in the small-size, scattered, and large-quantity forms.

\section{RESEARCH METHODS}

\subsection{Comprehensive measurement of rural development level}

\subsubsection{Indicator system}

From the perspective of element composition, the rural region system is an open system with certain structures and functions, which is constituted by interactions of various elements such as natural endowments, location conditions, economic foundation, human resources, and cultural customs within a certain rural area [17], which is closely associated with population, land, and industry [21]. Of which, natural environment elements such as topography, landform and resource endowments are natural backgrounds and spatial carriers for rural development. Besides, economic elements constituted by industrial development and economic foundation determine the current economic development level and future economic potential via path dependence. And the subjective initiatives of subjects such as the local government, enterprises, capable brains, and farmers for rural development are the prerequisite for breaking through the "bottleneck" in development and realizing sustainable development in the rural area. Moreover, the settlement environment also has a great impact on industrial development in the rural area and flow of rural subjects, thereby affecting the development in the rural development. In consequence, an evaluation indicator system is constructed from the dimensions of rural subjects, industrial development, resource endowments and human settlements (Table 1) upon comprehensive considerations in the comprehensiveness, scientificity, representativeness, and data availability of the evaluation indicators.

\subsubsection{Data standardization}

The evaluation indicator system of rural comprehensive development is composed of various indicators. Since different indicators have different positive and negative efficacies and dimensions, indicator data should be processed in standardization. Data standardization processing can be expressed as:

$$
\begin{aligned}
& \text { Positive indicator: } x_{i j}{ }^{\prime}=\frac{x_{i j}-\min \left(x_{i j}\right)}{\max \left(x_{i j}\right)-\min \left(x_{i j}\right)} \\
& \text { Reverse indicators: } x_{i j}{ }^{\prime}=\frac{\max \left(x_{i j}\right)-x_{i j}}{\max \left(x_{i j}\right)-\min \left(x_{i j}\right)}
\end{aligned}
$$

here, $x_{i j}{ }^{\prime}$ is the standardized value of the indicator $j$ of the administrative village $i$, and $x_{i j}$ is an actual value. $\max \left(x_{i j}\right)$ and $\min \left(x_{i j}\right)$ are the maximum and minimum values of the indicator $j$ of the administrative village $i$, respectively.

\subsubsection{Weight determination}

This research determined the indicator weight using the Entropy method, so as to demonstrate the contributions of various indicators to the measurement result in objective and fair manners. Steps for calculation are presented below. At first, calculate the proportion of the jth indicator of the ith administrative village:

$$
P_{i j}=\frac{x_{i j}}{\sum_{i=1}^{n} x_{i j}}(j=1,2, \cdots m)
$$

The entropy ej of the jth indicator is calculated:

$$
e_{j}=-k * \sum_{i=1}^{m} P_{i j} \ln \left(P_{i j}\right)
$$

The diversity factor of the jth indicator is calculated:

$$
g_{j}=1-e_{j}
$$

The weight of the jth index is calculated:

$$
W_{j}=\frac{g_{j}}{\sum_{j=1}^{m} g_{j}}
$$

Finally, the scores of the 4 dimensions of various evaluation units and the rural development level are calculated:

$$
S_{i}=\sum_{j=1}^{m} W_{j} * P_{i j}(i=1,2, \cdots n)
$$

here, $k=1 / \ln (m) ; m$ is the number of samples; and $S_{i}$ is the evaluation score of various dimensions of the village. Note that the greater the $S_{i}$ value, the better the evaluation result of the dimension. 
Table 1. System of indicators for evaluating the level of comprehensive rural development

\begin{tabular}{|c|c|c|c|c|}
\hline Criterion layer & Indicator & $\begin{array}{c}\text { Definitions of calculation method and } \\
\text { indicator }\end{array}$ & Weight & Efficiency \\
\hline \multirow{4}{*}{$\begin{array}{l}\text { Rural subject } \\
\quad(0.1917)\end{array}$} & Percentage of permanent population $\left(x_{l}\right)$ & Percentage of permanent population & 0.0585 & + \\
\hline & Proportion of labor force in the village $\left(x_{2}\right)$ & Number/ proportion of labor force & 0.0869 & + \\
\hline & $\begin{array}{l}\text { Proportion of population over } 65 \text { years old } \\
\left(x_{3}\right)\end{array}$ & Proportion of the elderly over 65 years old & 0.0270 & - \\
\hline & $\begin{array}{c}\text { Percentage of marginal households and } \\
\text { monitoring households }\left(x_{4}\right)\end{array}$ & $\begin{array}{l}\text { Percentage of marginal households and } \\
\text { unstable households in getting out of poverty }\end{array}$ & 0.0193 & - \\
\hline \multirow{5}{*}{$\begin{array}{c}\text { Industrial } \\
\text { development } \\
\left(\begin{array}{l}0.3031)\end{array}\right.\end{array}$} & Panting-cutlure development level $\left(x_{5}\right)$ & Proportion of large-size planters and farmers & 0.0798 & + \\
\hline & Agricultural industrialization level $\left(x_{6}\right)$ & $\begin{array}{c}\text { Number of professional cooperatives and } \\
\text { enterprises }\end{array}$ & 0.0505 & + \\
\hline & $\begin{array}{l}\text { Non-agricultural industry development } \\
\text { level }\left(x_{7}\right)\end{array}$ & Number of self-employed people & 0.0854 & + \\
\hline & Economic development level $\left(x_{8}\right)$ & Village collective economic income & 0.0438 & + \\
\hline & Multiple crop index $\left(x_{9}\right)$ & Seeded area of crops/ cultivated area & 0.1808 & + \\
\hline \multirow{3}{*}{$\begin{array}{l}\text { Resource } \\
\text { endowment } \\
(0.2175)\end{array}$} & $\begin{array}{l}\text { Average slope of the administrative village } \\
\qquad\left(x_{10}\right)\end{array}$ & ArcGIS slope analysis, raster statistics & 0.0436 & - \\
\hline & $\begin{array}{c}\text { Average elevation of the administrative } \\
\text { village }\left(x_{11}\right)\end{array}$ & ArcGIS raster statistics & 0.1196 & - \\
\hline & Arable land area per capita $\left(x_{12}\right)$ & $\begin{array}{l}\text { Total cultivated land/ number of registered } \\
\text { population }\end{array}$ & 0.0616 & + \\
\hline \multirow{3}{*}{$\begin{array}{l}\text { Living } \\
\text { environment } \\
(0.2877)\end{array}$} & Income level of peasant households $\left(x_{13}\right)$ & Rural per capita net income & 0.0363 & + \\
\hline & Public service facility level $\left(x_{14}\right)$ & $\begin{array}{l}\text { Number of medical facilities and educational } \\
\text { facilities }\end{array}$ & 0.0322 & + \\
\hline & Infrastructure level $\left(x_{15}\right)$ & Road network traffic density & 0.0747 & + \\
\hline
\end{tabular}

\subsection{Divisions of hierarchical system and structure of villages and towns}

A reasonable village-town system is a significant safeguard for implement smart shrinkage in villages, which is related to the rational allocation of various resources and the performance of the overall function. The level of village, a basic unit of the village-town system, can be determined in accordance with the score of the comprehensive development level, which is also linearly associated with the comprehensive development level of the village. Ideally, there is a positive correlation between the comprehensive development level and the rank of village level. Hence, the study determined the hierarchical system and structure of villages and towns through measuring the relationship between the fourdimension scores of each evaluation unit and the rank of the evaluation unit on the basis of referring to the rank-size model of G.K.Zipf. The rank-size rule [22] is a model originally applied to investigate the size distribution of the regional urban system, which has scientific significance upon scholars' constant improvement and revisions [23, 24]. It can be calculated as:

$$
P_{r}=P_{1} r^{-q}
$$

Here, $r$ represents the scores regarding the rural subject, industrial development, resource endowment, habitat environment, and comprehensive development level in descending orders; Pr and P1 represent the village size in the $r$ order, and the village size in the first order in the township hierarchy, respectively; and q is the Zipf's index (constant), which is calculated as a parameter reflecting the rank-size distribution of village. When $\mathrm{q}=1$, it demonstrates that the rank-size distribution of village is the optimal structure distributed under natural conditions, presenting a reasonable size structure. When $q<1$, it implies that the ranked distribution of village size is concentrated. More precisely, villages at the middle and low ranks are well developed with a small number of high-ranking villages, presenting a less prominent polarization. Currently, it has a limited effect on radiating the surrounding villages for the weak primacy ratio of highranking villages is weak. When $q>1$, it indicates that the ranked distribution of village size in the study area is relatively concentrated; the village in primary has a strong monopoly position, and high-ranking villages have prominent advantages with marked polarization effects. On the contrary, small and medium-ranking villages are developed insufficiently, showing a significant unbalanced development trend among villages.

\subsection{Division of rural types}

To begin with, evaluation results of rural subject, industrial development, resource endowment and habitat environment were partitioned into high, medium, and low levels, as well as assigned as 3,2, and 1 using the natural fracture function in arcg is 10.2. Then, permutation and combination were performed. In total, there are 81 methods for permutation and combination. Moreover, the evaluation unit was divided into three rural development types: Agglomeration for improvement, equilibrium and stability, as well as relocation and merger, which are corresponding to the hierarchical system of central villages and general villages, and merged villages. Of which, the combination methods of equilibrium and stable type are complex and huge in size. Thus, those villages excluding the agglomeration type for improvement as well as relocation and merger are incorporated into equilibrium and stable type. Specific division criteria, combination methods, and basic characteristics are shown in Table 2 . 
Table 2. Criteria for identifying the type of rural development

\begin{tabular}{|c|c|c|c|c|}
\hline $\begin{array}{c}\text { Type of rural } \\
\text { development }\end{array}$ & $\begin{array}{c}\text { Hierarchical } \\
\text { system }\end{array}$ & $\begin{array}{c}\text { Classification standard and } \\
\text { combination }\end{array}$ & $\begin{array}{c}\text { Number of } \\
\text { combination }\end{array}$ & Basic features \\
\hline $\begin{array}{l}\text { Agglomeration for } \\
\text { improvement }\end{array}$ & Key villages & $\begin{array}{l}(3,3,3,3),(2,3,3,3),(3,2,3,3) \\
(3,3,2,3),(3,3,3,2),(3,3,3,1) \\
(3,3,1,3),(3,1,3,3),(1,3,3,3)\end{array}$ & 9 & $\begin{array}{l}\text { With marvelous resource and environment } \\
\text { carrying capacity, the rural subject has } \\
\text { comparative advantages over favorable } \\
\text { resource endowment in the region, high } \\
\text { industrial development level, and good habitat } \\
\text { environment. It has a certain influence and } \\
\text { demonstration effect on stimulating the } \\
\text { surrounding development. }\end{array}$ \\
\hline $\begin{array}{l}\text { Equilibrium and } \\
\text { stability type }\end{array}$ & $\begin{array}{l}\text { General } \\
\text { villages }\end{array}$ & $\begin{array}{c}(2,2,2,2),(2,2,1,1),(2,1,1,2) \\
(1,1,2,2),(1,2,2,2),(2,2,2,1) \\
(2,2,1,2),(2,1,2,2),(1,2,2,2) \\
\ldots \ldots .\end{array}$ & 63 & $\begin{array}{l}\text { At this stage, features of rural development } \\
\text { were insignificant. However, the villages still } \\
\text { exist with a safe and stable environment, } \\
\text { average resource endowment conditions, a } \\
\text { great space for improvement based on certain } \\
\text { industrial foundations, average conditions in } \\
\text { other aspects take up a great proportion among } \\
\text { all the villages in the county. They are key } \\
\text { priorities in rural revitalization. }\end{array}$ \\
\hline $\begin{array}{l}\text { Relocation and } \\
\text { merger }\end{array}$ & Merged villages & $\begin{array}{l}(1,1,1,1),(1,1,1,2),(1,1,1,3) \\
(1,1,2,1),(1,2,1,1),(2,1,1,1) \\
(1,1,3,1),(1,3,1,1),(3,1,1,1)\end{array}$ & 9 & $\begin{array}{l}\text { Areas with a large scale relocation, a critical } \\
\text { deprivation of rural subjects, fragile ecological } \\
\text { environment, poor resource endowment } \\
\text { conditions, deficiency in comparative } \\
\text { advantages, and frequent natural disasters. }\end{array}$ \\
\hline
\end{tabular}

* Data source: Based on the indicator data in Table 1, the data were standardized and then calculated by the Entropy method. Numbers in parentheses indicate the rank in the evaluation of rural elements. High value area, medium value area, and low value area correspond to 3 , 2, and 1 , respectively. For instance, $(3,3,3,3)$ refers to high values in rural subject, industrial development, resource endowments and human settlements.

\section{RESULT ANALYSIS}

\subsection{Analysis of rural development level}

4.1.1 Characteristics of spatial pattern of rural development level

Evaluation results of various dimensions of rural subject, industrial development, resource endowment and habitat environment are presented in a spatial pattern of being scattered and being locally agglomerated (Figure 3 ).

(1) Obvious spatial agglomeration characteristics can be found among rural subjects. High-value areas are concentrated in the southwestern Wangmo county with flat terrain and low altitude, and Wangmu Street, Pingdong Street, and Zhexiang Town have dominant advantages in rural development. Lowvalue areas are mainly distributed in towns and villages in the northeastern Wangmo county with high altitude and steep terrain, such as Lewang Town and Dayi Town, where there is a great loss of rural population.

(2) Industrial development is satisfactory as a whole, and villages at the high and medium levels account for $70.63 \%$. The characteristics of being scattered as a whole and being locally agglomerated are presented in space. And high-value areas are concentrated in the northern county. In addition, the eastern and northern parts of the Wangmo county feature large-size population relocation with a great loss of rural population for high terrain, and inconvenient transportation. Nevertheless, that area is abundant in tea tree resources and has a long history in tea tree planting. At present, 81,881 ancient tea trees were identified in those areas. After the relocation, the local government has completed the transfer of more than 9,000 acres of land and extended the tea industry chain through introducing the involvement of social capitals, pushing forward the integrated development of the primary, secondary and tertiary industries.

(3) Resource endowments are progressive from north to south, demonstrating hierarchical structures of "high, medium and low" in space. The southern county is located in the Green Corridor between the north and south of Panjiang in Guizhou, which has excellent hydrothermal conditions, and ample land resources for its terrain is dominated by hills and valley basins together with collective economic source and stabilized means of increasing farmers' income. Conversely, the northern county with high elevation and steep terrain has poor resource endowment conditions.

(4) In terms of habitat environment, a high-value agglomeration area centered on the county downtown is formed for habitat environment. Note that the infrastructure and public facility welfares are deficient in the northwest-southeast area of the county. The northern county has greatly improved transportation infrastructure, public service facilities, and living environment thanks to the supports of targeted poverty alleviation for transportation, medical care, and education in deeply impoverished areas in recent years, although it has rugged terrain and poor natural conditions.

\subsubsection{Characteristics of rank-size distribution of villages}

The research drafted the rank-size fitting curve of the scores of various dimensions through fitting with power functions with the rank as the independent variable, and comprehensive level score as well as various element scores as dependent variables. According to the findings, the $q$-value of the fitting curve equations of the comprehensive level of villages in Wangmo County and the scores of the four dimensions are less than 1 (Figure 4), indicating that the hierarchical structure of villages and towns is stable as a whole. Specifically, the medium-ranking villages are well developed, while the highand-low ranking villages are lagging in development, presenting a spindle structure of being small on both ends, and large in the middle". By this time, high-ranking villages have weak primacy, limited radiations in surrounding villages, a weak degree of spatial polarization, and insignificant 
trickledown effect. Hence, the rural development is at the polarization stage of dominant villages. As can be observed from the comparison between the fitting function and the actual scatter diagram, the actual development levels of the high-ranking and low-ranking villages corresponding to the
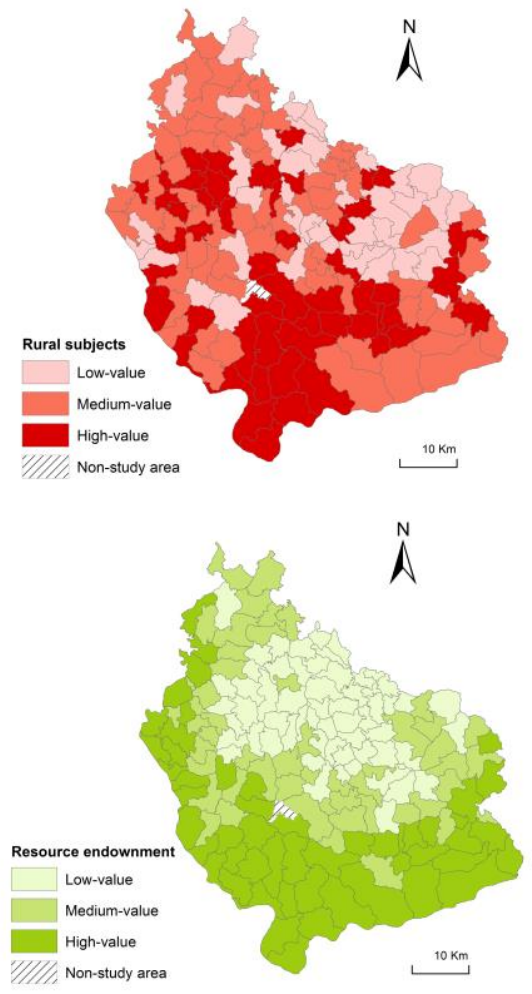

four dimensions are lower than the theoretical value with a lagging development level. But the actual development level of the medium-ranking village is higher than or approaching the theoretical value with an advanced development level.

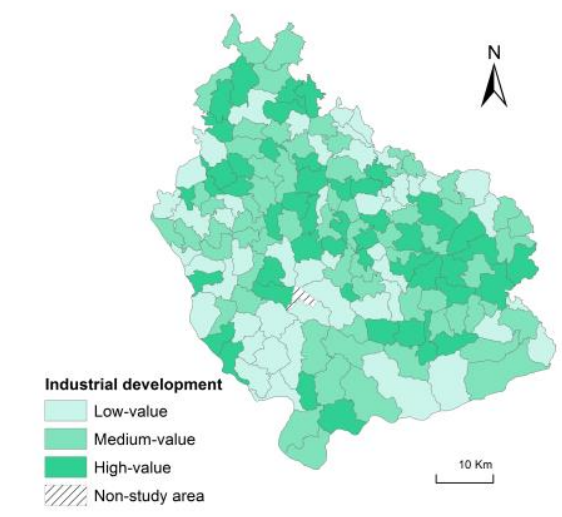

Figure 3. Spatial pattern of rural element evaluation results
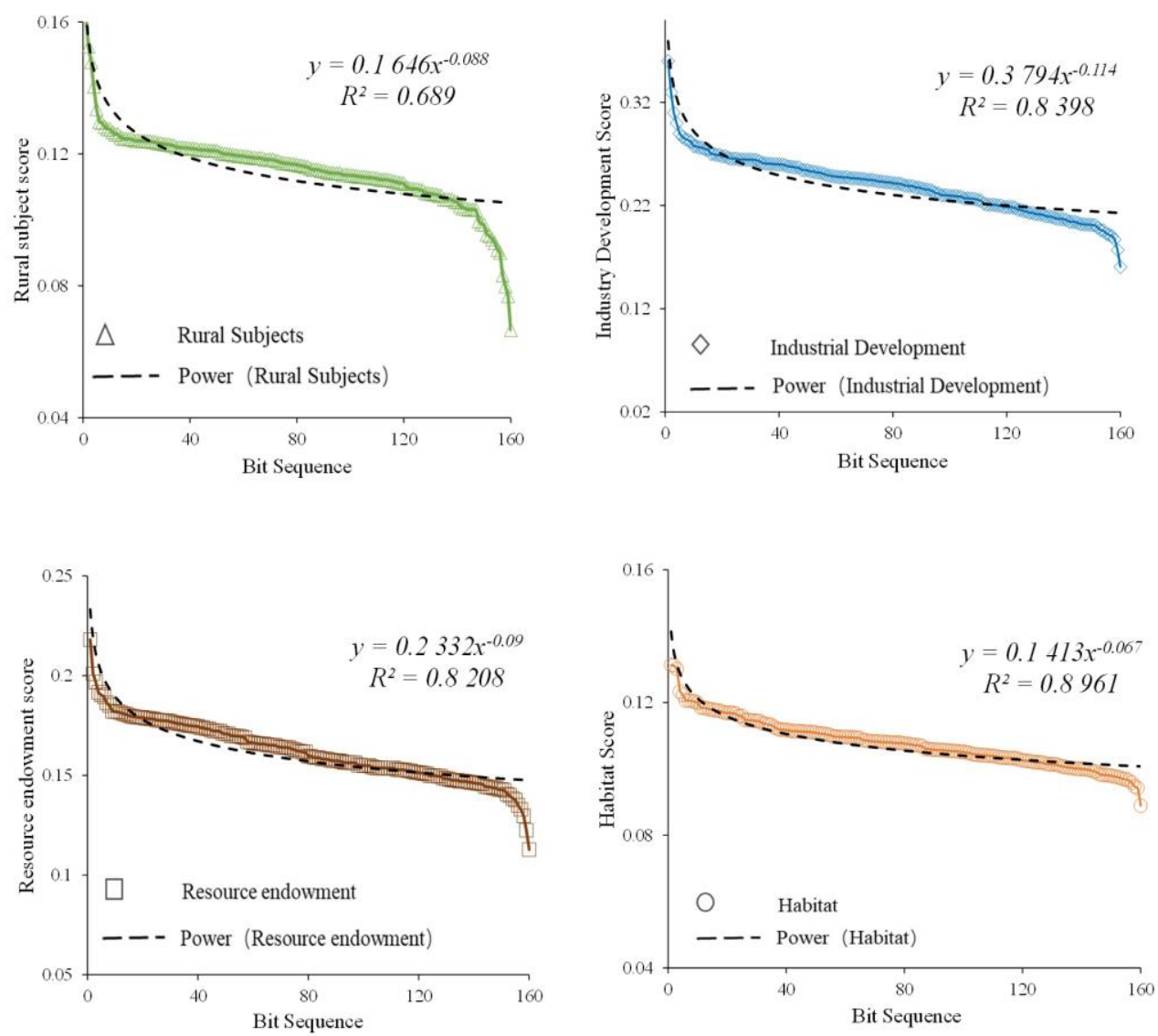

Figure 4. Fitting curves for different elements and their position order 


\subsection{Village type identification and varied development Paths}

(1) Agglomeration type for improvement. There are 46 villages of agglomeration for improvement, including Bamao Village in Zhexiang Town, Xintun Village in Xintun Street and Sanglang Village in Sanglang Town (Figure 5), accounting for $28.75 \%$. From the perspective of spatial distribution, the village type is led by township residence, which is not completely consistent with the village where the township residence is located for its characteristics of overall dispersion and local agglomeration. In view of the development of the village type, the central function of township residence should be first strengthened to promote the flow of urban and rural elements and to optimize the rank-size distribution of villages. Next, for the villages in the urban development space, actively promoting the integrated construction of urban and rural infrastructure can promote resources sharing, elements exchanging, advantages complementing to well stimulate the radiation. Moreover, talent supports can be provided for rural development by means of establishing and improving the incentive mechanism for returning to the hometown to start a business, focusing on cultivating new professional farmers, encouraging scientific and technological talents to go to the countryside and mining local talents.

(2) Equilibrium and stability type. Most of the villages in the county belong to this village type, covering 99 villages, accounting for $60 \%$. Note that they are distributed in patches. Villages of equilibrium and stability type have resources and environmental carrying capacity that can provide essential supports for village development. During targeted poverty alleviation, traffic conditions and living environment in those villages have been substantially improved with some rudiments of industrial development. Nevertheless, development characteristics at this stage are insignificant with a common phenomenon of population loss in rural areas. In addition, evaluation results of various dimensions are at the medium level of the county, indicating that these villages possessing huge development potentials should be strengthened and expanded under rural revitalization. Firstly, the village type should actively cultivate new business entities such as large planters, concern the long-term cultivation of the industry, absorb the participation of market players, and extend the regional industrial chain with expanding regional industries as its development direction. Secondly, it should cultivate and expand characteristic and advantageous industries and emphasize brand response and enhance market competitiveness centering on the regional industrial system. In the meantime, it should prevent and resolve natural risks of industrial development, and enhance agricultural production facilities and rural production and living conditions with the help of carrying out land reclamation projects and human settlements improvement projects.

(3) Relocation and merger type. According to division planning and evaluation results of Wangmo County, 18 relocation and merger villages (accounting for $11.25 \%$ ), including Laozhai Village and Liuli Village, were selected, which are distributed in the areas with high mountain and steep slopes in the northern county. The village type features poor resource and environmental carrying capacity and development suitability conditions, fragile ecology, and hidden dangers of geological disasters, which is located in the area where is more likely to suffer from geological disasters.
Hence, it is not suitable for further development and construction, such as Laozhai Village in Dayi Town and Tie Town in Jiaona Town. Lu Village and Dajian Village in Shitun Town. Moreover, there are relocated villages with small population size. For instance, Shanhua Village in Mashan Town has only 29 households and 155 villagers after the relocation. The village type should strictly control the size of settlements, reasonably determine the resource allocation in the area, promote the natural extinction of such settlement, and gradually guide the relocation to the surrounding key villages or towns on the premise of ensuring the basic living standards of villagers. Meanwhile, homestead land reclamation, ecological restoration should be also implemented.

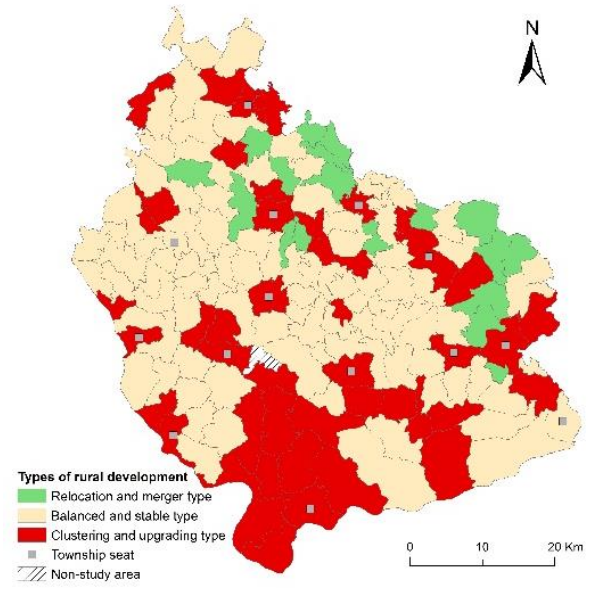

(a) Village types

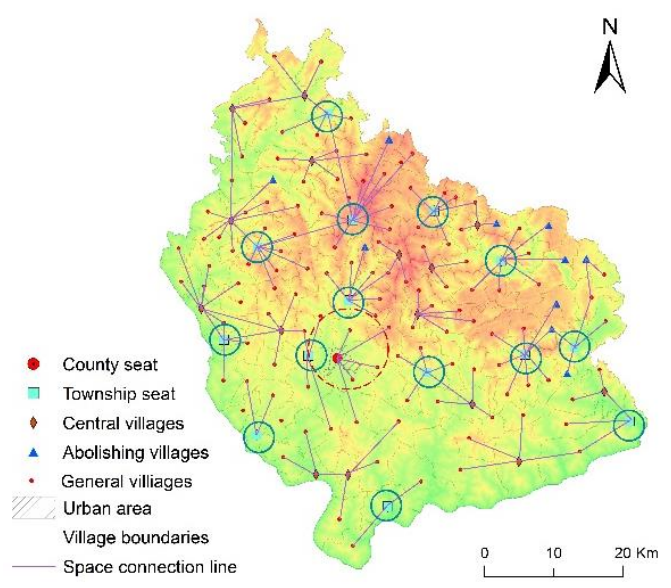

(b) Layout optimisation

Figure 5. Village types and spatial layout optimisation

\section{CONCLUSIONS}

Three links that the optimization of village spatial layout under the perspective of smart shrinkage are proposes in the research (Figure 6):

(1) Grasping the current situation of village development and examining the comprehensive development level of villages from the dimensions of resource endowment, village subject, industry development base and human living environment are the primary prerequisites for village layout optimization. The results of the study show that the development level of villages in Wangmo County varies significantly, and each evaluation dimension shows a trend of relative dispersion overall and relative concentration locally. 


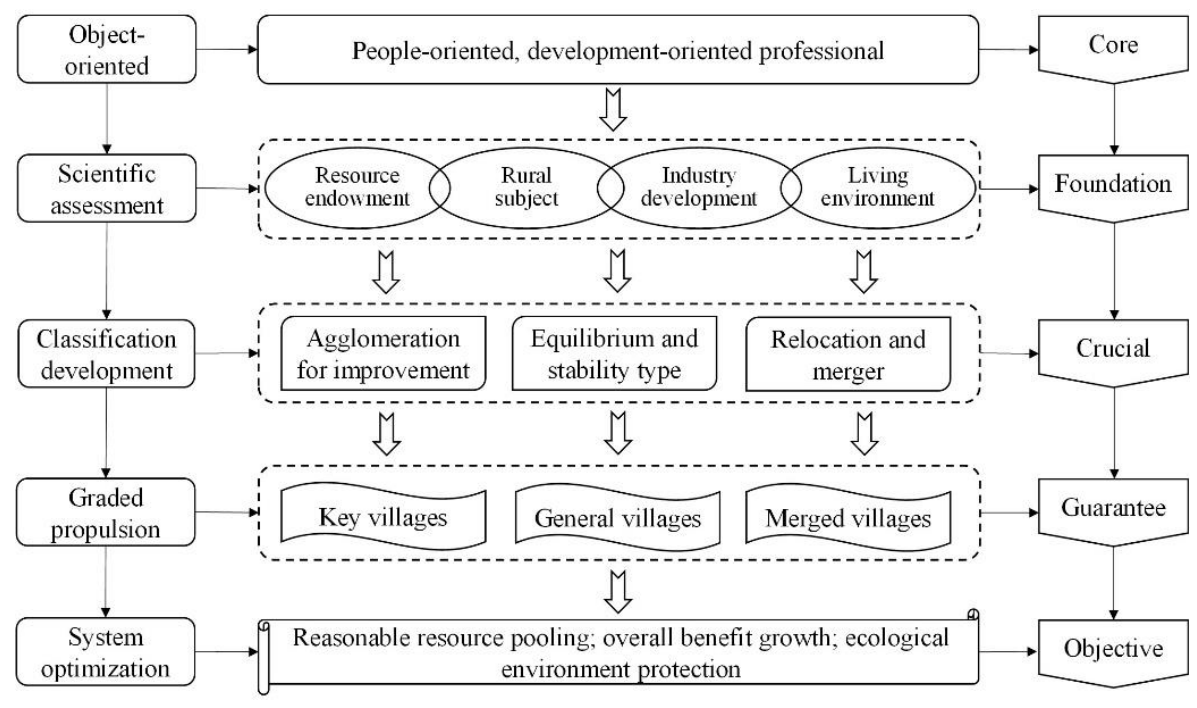

Figure 6. Optimal village layout path from a smart shrinkage perspective

(2) Dividing the development types of villages and clarifying the development directions of different types of villages are the key links of village layout optimization. Village types in the study area were divided into agglomeration type for improvement, equilibrium and stability type, and relocation and merger type according to the evaluation results and the actual development of the area, and the development direction of each type of villages is clearly defined. A spindle-shaped structure of "being small on both ends, and large in the middle" was observed in terms of quantity.

(3) Constructing a reasonable village-town system, and allocating limited social resources to villages that can stimulate the surrounding development is an important guarantee for optimizing the village layout. For this purpose, this study constructs a village-town system featuring centralvillage, general-village and merged-village in Wangmo County according to the three types of villages, and proposes to enhance influence and demonstration effect on stimulating the surrounding development by continuously strengthening the central function of central-village. Meanwhile, the residents of the merged-village should be gradually guided to relocate to the surrounding key villages and towns on the premise of ensuring the basic living standards of villagers. Homestead land reclamation and ecological restoration should be also implemented.

\section{DISCUSSIONS}

Assessing the level of rural comprehensive development and grasping the current situation of rural development are the primary premise of village layout optimization. The index system was constructed from the dimensions of resource endowment, village subject, industry development base and human living environment. Affected by the difficulty in obtaining data, the important indicators affecting rural development, such as traffic location, characteristic culture and tourism resources, were ignored. However, in the actual development of villages, the villages with good traffic location and tourism resources or certain characteristics have much higher development potential and speed than other villages; In addition, in the selection of specific indicators, the indicators are mostly quantitative indicators, reflecting the quality of development indicators are few, the evaluation results are inevitably deviated from the actual situation.

The academic community has carried out a large number of researches on rural classification, and classified a variety of rural types from the aspects of industry, terrain, economic development level, village size, location conditions and so on, which has accumulated rich experience for village classification. In 2018, China released National Strategic Plan for Rural Revitalization (2018-2022), which clearly put forward four village types and their classification and development strategies, agglomeration type for improvement, equilibrium and stability type, characteristic protection and relocation and merger type. However, there is a lack of clear instructions or criteria on how to classify villages. According to the actual development of villages in Wangmo County, the study classifies village development as agglomeration type for improvement, equilibrium and stability type, and relocation and merger type, does not cover the characteristic protection type. However, as a typical ethnic minority region in China, village construction and development in Wangmo County has significant ethnic characteristics, and no matter which type of village it is, the preservation of characteristics should be the focus of village construction and development.

Village layout should be optimized from the perspective of smart shrinkage under the guidance of county and the reconstruction of internal space in the rural area. In that case, it is imperative to analyze the characteristics of rural development and the village-town system apart from comprehensively evaluating the potential of rural development. By doing so, optimization of rural spatial layout, industrial structural upgrading, and allocation of public resources should be controlled. What's more, rural living, production, and ecological space should be also reconstructed through the extensive exploration of various village types with focuses on layout of rural residential areas, spatial layout of rural industries, infrastructure and public service facilities, and the improvement of human settlements [17].

The major innovation of the study is that by introducing smart shrinkage theory into the research of rural development, the optimization of village layout is realized on the premise of scientifically evaluating the potential of rural development and the characteristics of its rank-size distribution, thereby enriching the theoretical system of smart shrinkage. However, significant regional differences are witnessed in development 
in different rural areas due to the vast territories in China [25]. The study has taken the example of an impoverished mountainous area provides a reference significance for transformation in the rural area within a certain territory and its planning response. It is noteworthy that it is unclear whether the finding is universally applicable to rural development in other areas. Furthermore, observational analysis of long-term sequence should be handled for mastering characteristics at the rural development stage. However, the research still has its defections since only data of 2019 were adopted due to limited access to data. Therefore, future research should be conducted with the help of observational data of long-term sequence so as to observe the dynamic variations of rural development in different areas.

\section{ACKNOWLEDGMENT}

This work is supported by Chongqing Technology Foresight and System Innovation Project (Grant numbers: cstc2020jsyj-zzysbAX0077).

\section{REFERENCES}

[1] Liu, Y., Li, Y. (2017). Revitalize the world's countryside. Nature, 548: 275-277. https://doi.org/10.1038/548275a

[2] Cao, Z., Zheng, X.Y., Liu, Y.S., Li, Y.R., Chen, Y.F. (2018). Exploring the changing patterns of China's migration and its determinants using census data of 2000 and 2010. Habitat International, 82: 72-82. https://doi.org/10.1016/j.habitatint.2018.09.006

[3] Yang, Z., Dunford, M. (2018). City shrinkage in China: Scalar processes of urban and hukou population losses. Regional Studies, $\quad$ 52(8): https://doi.org/10.1080/00343404.2017.1335865

[4] Qiang, Z., Zhang, H., Liu, Z. (2018). Rural revitalization: Strategic choice from decline to revival. Economy and Management, 32(1): 6-11. https://doi.org/10.3969/j.issn.1003-3890.2018.01.003

[5] Zhao, M., You, L., Chen, C. (2015). Smart shrinkage of rural human settlements and its planning strategies. City Planning Review, 39(7). https://doi.org/10.11819/cpr20150703a

[6] Li, Y.H., Westlund, H., Liu, Y. (2019). Why some rural areas decline while some others not: An overview of rural evolution in the world. Journal of Rural Studies, 68: 135143. https://doi.org/10.1016/j.jrurstud.2019.03.003

[7] Beauregard, R. (2015). Shrinking Cities. In: James D W. International Encyclopedia of The Social \& Behavioral Sciences (second edition). Oxford: Elsevier, 917-922.

[8] Popper, Deborah, E., Frank, J. (2002). Small Can Be Beautiful. Planning.

[9] Pallagst, K., Schwarz, T., Popper, F.J., Hollander, J.B. (2009). Planning shrinking cities. Progress in Planning, 72(4).

[10] Haasea, A., Herfertb, G., Kabischa, S., Steinfhrerc, A. (2012). Reurbanizing Leipzig (Germany): Context Conditions and Residential Actors (2000-2007). European Planning Studies, 20(7): 1173-1196. https://doi.org/10.1080/09654313.2012.674349

[11] Wiechmann, T., Pallagst, K.M. (2012). Urban shrinkage in Germany and the USA: A comparison of transformation patterns and local strategies. Int J Urban Reg Res, 36(2): 261-280. https://doi.org/10.1111/j.14682427.2011.01095.x

[12] Bowns, C. (2013). Shrinkage happens in small towns too!: Responding to de-population and loss of place in Susquehanna River Towns. Urban Design International, 18: 61-77. https://doi.org/10.1057/udi.2012.27

[13] Cao, L., Tan, J., Wei, L., Chen, Y. (2009). Development trends of villages and towns in China. Chinese Journal of $\begin{array}{lll}\text { Engineering } & \text { Science, } & \text { 21(2): }\end{array}$ https://doi.org/10.15302/J-SSCAE-2019.02.011

[14] You, L., Chen, C. (2019). Planning and implementing smart shrinkage of rural China: The case of Chengdu's rural settlement consolidation with SGME model. Journal of Regional and City Planning, 30(1): 62. https://doi.org/10.5614/jpwk.2019.30.1.5

[15] Long, H., Liu, Y. (2016). Rural restructuring in China. Journal of Rural Studies, 47: 387-391. https://doi.org/10.1016/j.jrurstud.2016.07.028

[16] Peters, D.J., Hamideh, S., Zarecor, K.E., Ghandour, M. (2018). Using entrepreneurial social infrastructure to understand smart shrinkage in small towns. Journal of Rural Studies, 64: 39-49. https://doi.org/10.1016/j.jrurstud.2018.10.001

[17] TU, S.S., Long, H.L. (2017). Rural restructuring in China: Theory, approaches and research prospect. Journal of Geographical Sciences, 27: 1169-1184. https://doi.org/10.1007/s11442-017-1429-x

[18] Qiao, J., Lee, J., Ye, X. (2016). Spatiotemporal evolution of specialized villages and rural development: A case study of Henan province, China. Annals of the Association of American Geographers, 2016(1): 1-19. https://doi.org/10.1080/00045608.2015.1086951

[19] Li, Y., Song, C., Huang, H. (2021). Rural resilience in China and key restriction factor detection. Sustainability, 13(3): 1080. https://doi.org/10.3390/su13031080

[20] Kong, X., Jin, L., Qie, Y., Zhang, Y.R., Xu, Y. (2014). Layout optimization of rural settlements based on pointaxis theory. Nongye Gongcheng Xuebao/Transactions of the Chinese Society of Agricultural Engineering, 30(8): 192-200. https://doi.org/10.3969/j.issn.10026819.2014.08.023

[21] Cheng, M.Y., Liu, Y.S., Jiang, N. (2019). Study on the spatial pattern and mechanism of rural population-landindustry coordinating development in Huang-Huai-Hai Area. Acta Geographica Sinica, 74(8): 1576-1589. https://doi.org/10.11821/dlxb201908007

[22] Nota, F., Song, S. (2008). Further analysis of the Zipf law: Does the rank-size rule really exist? Journal of Urban Management, 1(2): 19-31. https://doi.org/10.1016/S2226-5856(18)30058-X

[23] Batty, M., Longley, P., Fotheringham, S. (1989). Urban growth and form: scaling, fractal geometry, and diffusion-limited aggregation. Environment \& Planning A, 21(11): 1447-1472. https://doi.org/10.1068/a211447

[24] Liu, Z. (2013). Fractal theory and application in city size distribution. Information Technology Journal, 12(17): 4158-4162. https://doi.org/10.3923/itj.2013.4158.4162

[25] Liu, Y., Zang, Y., Yang, Y. (2020). China's rural revitalization and development: Theory, technology and management. Journal of Geographical Sciences, 30(12): 1923-1942. https://doi.org/10.1007/s1 1442-020-1819-3 